\title{
Functional Balance Assessment of Firefighters during Mass-Screening Examinations
}

\author{
Rachel M. Eiler, DAT, LAT, ATC*; Zachary K. Winkelmann, PhD, SCAT, ATC $\dagger$; and Kenneth E. Games PhD, \\ LAT, ATC $\ddagger$ \\ *NovaCare Rehabilitation, Minneapolis, MN; †University of South Carolina, Columbia SC; ¥Indiana State University, Terre Haute, \\ IN
}

\begin{abstract}
Firefighters are tactical athletes who are required to complete rigorous tasks as part of their job functions. The focus of this clinical outcomes assessment was to assess functional balance assessment through the use of the anterior reach test with and without personal protective equipment (PPE) during a mass-screening examination. The screening was completed with 61 active firefighters in a local fire department with access to athletic training services. The results of the anterior reach assessment identified a significant difference of a firefighter's anterior reach when donning and doffing PPE. Anterior reach distances were significantly reduced $(P \leq 0.001)$ on the right leg with (mean $=55.78 \mathrm{~cm} \pm 7.53 \mathrm{~cm}$ ) and without PPE (mean $=58.92 \mathrm{~cm}$ $\pm 6.47 \mathrm{~cm})$. Similarly, significant decrements $(P=0.003)$ in left leg anterior reach distance in firefighters donning (mean $=57.67 \mathrm{~cm} \pm 8.25 \mathrm{~cm}$ ) and doffing (mean $=59.82 \mathrm{~cm} \pm$ $6.31 \mathrm{~cm})$ PPE. Clinical application of these findings suggests that healthcare providers working with tactical athletes, specifically firefighters, should consider the risks associated with donning PPE such as functional balance deficits.
\end{abstract}

Key Phrases

Pre-participation exams and screenings, emerging settings

\section{Correspondence}

Dr. Zachary K Winkelmann, University of South Carolina, 1300 Wheat Street, Columbia, SC 29208.

E-mail:winkelz@mailbox.sc.edu

Twitter: @zachwinkelmann

Full Citation

Eiler RM, Winkelmann ZK, Games KE. Functional Balance Assessment of Firefighters during Mass-Screening Examinations. Clin Pract Athl Train. 2020;3(2):45-49. https://doi.org/1031622/2020/0002.6.

Submitted: December 19, 2019 Accepted: May 15, 2020

\section{PATIENTS}

$S_{i x /}$ ixty-one firefighters from a Midwestern fire department were included in this mass-screening examination. All of the firefighters were

Copyright $($ by Indiana State University All rights reserved. ISSN Online 2577-8188 considered career, full-time employees of the city municipality. Sixty firefighters identified as male and 1 firefighter identified as female. The firefighters ranged in age from 25 to 64 years of age (mean $=41.07 \pm 9.23$ years) and had between two and 34 years of experience (mean $=15.31 \pm 9.41$ years) in the fire service. The body composition of the firefighters was of average height $(28.03 \pm 1.08 \mathrm{~cm})$ and aboveaverage mass $(105.58 \pm 20.87 \mathrm{~kg})$.

During the intake process, the firefighters completed a past medical history form. From this process, 12 firefighters (19.7\%) reported having chronic pain, 16 firefighters $(26.2 \%)$ reported a previous head/neurological injury, 42 firefighters $(68.9 \%)$ reported having a previous surgery, and 24 firefighters $(39.3 \%)$ indicated an ongoing orthopedic injury at the time of the mass-screening examination. It is important to indicate here that while $39.3 \%$ of the firefighters reported an ongoing injury, none of these individuals were on restricted or light duty. Thus, they were required to execute and perform all job-related tasks.

\section{INTERVENTION}

The intervention was a three-day, mass-screening event at the fire department's training center. The firefighters arrived at the firefighter training center during their shift in crews of three to seven people. Each firefighter completed a past medical history form and patient-reported outcome measures via an online survey (Qualtrics, Inc, Provo, UT). Once the patients completed the online survey, they proceeded to complete a series of functional screenings throughout the training center. Figure 1 outlines the flow chart of MassScreening Intervention Process. 


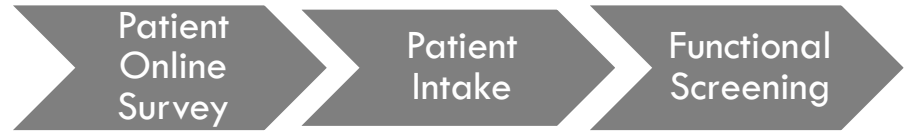

Figure 1. Flow Chart of Mass-Screening Intervention Process

The first stage of the functional screening included patient intake (height, weight, leg length, tibial tuberosity height, and hand length), the weight bearing lunge test, and the closed kinetic chain upper extremity stability test. Once all patients completed these stations, they proceeded to the second stage of the function screenings that consisted of the anterior reach portion of the Y-Balance Test, the Landing Error Scoring System (LESS), and the Functional Movement Screen (FMS). The firefighters completed each of these tests while donning their station attire that included a t-shirt, athletic shorts/pants, and tennis shoes, or while donning their personal protective equipment (PPE) which included their jacket, pants, boots, helmet, mask, and condensed air tank. During the anterior reach, the firefighter's mask was not connected to the condensed air tank during the completion of the anterior reach. The mask is the piece of equipment that covers the firefighter's face into which the condensed air tank attaches to provide the firefighter with oxygen. Once the patient completed the tests while donning and doffing their PPE, their mass-screening examination was completed.

\section{OUTCOME MEASURES}

The focus of this clinical outcomes' assessment was dynamic balance assessed using the anterior reach portion of the Y-Balance Test. The YBalance Test measures dynamic balance using single limb stance excursion. ${ }^{1}$ Prior to the $Y$ Balance Test, the Star Excursion Balance Test (SEBT) was used to identify chronic ankle instability, at-risk athletes for lower extremity injury, and assess overall physical performance. ${ }^{1}$ The Y-Balance Test was developed to improve the repeatability of the SEBT.1 The anterior reach

Copyright (C) by Indiana State University All rights reserved. ISSN Online 2577-8188 assessment was utilized because previous research suggests that asymmetries in the anterior direction indicated balance deficits that increased the risk for injury. ${ }^{2,3}$ Specifically, the anterior reach has high intrarater reliability at $0.91 .1,2$ To be mindful of time guided by the literature, we only assessed the anterior reach out of the three directions for the Y-Balance Test.

Prior to the firefighter completing the assessment, the athletic trainer provided verbal and modeling instruction on how to complete the anterior reach assessment of the Y-Balance Test. During the anterior reach assessment, each firefighter successfully completed the test three times while donning PPE (Figure 2) and three times doffing PPE (Figure 3) for a total of six trials of the anterior reach completed using an established protocol.' The order was not controlled for the patients to start with or without their PPE. The anterior reach test was completed using the $Y$ Balance Test Kit, which includes three pipes in the anterior, posteromedial, and posterolateral direction. ${ }^{1}$ For the mass-screening examination, only the anterior pipe was measured. The pipe was marked in 0.5 centimeters increments for measurements, where the firefighter pushes the reach indicator box along the pipe, marking the determination of the reach distance, and returning

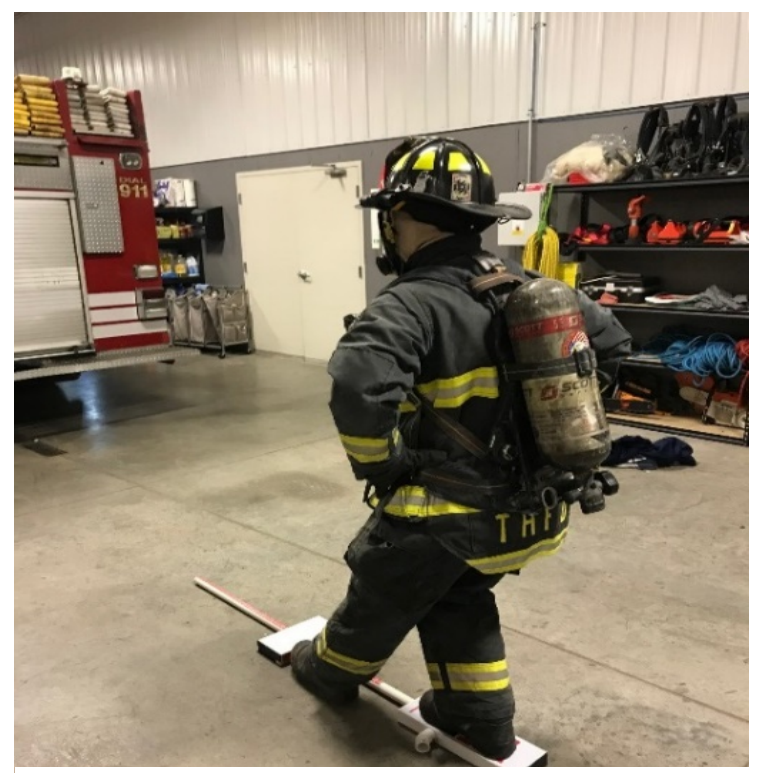

Figure 2. Anterior Reach Assessment with Personal Protective Equipment 
to the starting point while maintaining their balance on their stance leg. ${ }^{1}$

Once all patients completed the anterior reach assessment, the data were entered into a custom spreadsheet application and analyzed in a commercially available statistics package. First, the absolute reach distance was calculated by summing the three reach distances and dividing by three for the average on the right and left leg with and without PPE. Next, the data were normalized by dividing the maximum reach distance in each leg for each condition by the limb length of the patient. This number was multiplied by 100 to calculate the relative anterior reach distance. Normalizing the data occurred to be able to compare the data among the individuals with different leg lengths.

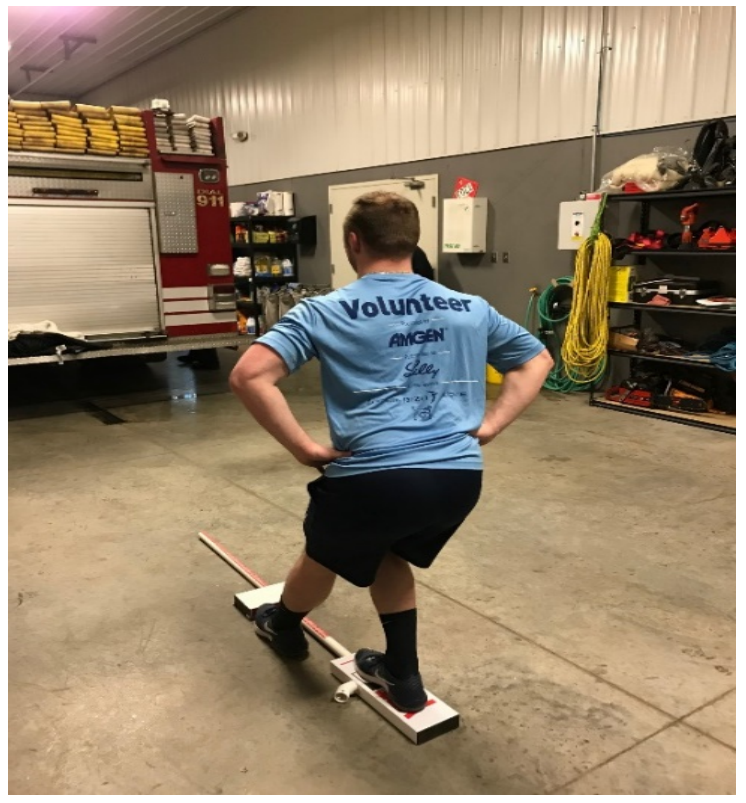

Figure 3. Anterior Reach Assessment Without Personal Protective Equipment

\section{RESULTS}

The majority $(54 / 61,88.5 \%)$ of the firefighters were self-reported right leg dominant. Table 1 provides the descriptive statistics for the anterior reach assessment. A paired sample t-test was utilized to analyze the data. Results of the data analysis identified a significant difference $(P<$ 0.000 ) for the right leg anterior reach distance when the firefighters were doffing their PPE (mean

Copyright (C) by Indiana State University All rights reserved. ISSN Online 2577-8188
$=58.92 \mathrm{~cm} \pm 6.47 \mathrm{~cm}$ ) as compared to when they were donning their PPE (mean $=55.78 \mathrm{~cm} \pm 7.53$ $\mathrm{cm})$. Similar results were identified on the left leg with a significant difference $(P=0.003)$ for anterior reach distance donning and doffing PPE.

Table 1. Anterior Reach Results

\begin{tabular}{lccc}
\hline Condition & $\begin{array}{c}\text { Mean } \\
(\mathbf{c m})\end{array}$ & $\begin{array}{c}\text { Standard } \\
\text { Deviation } \\
(\mathbf{c m})\end{array}$ & $\begin{array}{c}\text { Standard } \\
\text { Error } \\
(\mathbf{c m})\end{array}$ \\
\hline $\begin{array}{l}\text { Right Leg }- \\
\text { PPE }\end{array}$ & 55.78 & 7.53 & 0.96 \\
$\begin{array}{l}\text { Right Leg - } \\
\text { No PPE } \\
\text { Left Leg - }\end{array}$ & 58.92 & 6.47 & 0.83 \\
$\begin{array}{l}\text { PEE } \\
\text { Left Leg - }\end{array}$ & 57.67 & 8.25 & 1.06 \\
No PPE & 59.81 & 6.30 & 0.81 \\
\hline
\end{tabular}

PPE $=$ Personal Protective Equipment

After normalizing the measurements per patient, we identified a significant difference in relative anterior reach distance for the right $(P \leq 0.01)$ and left $(P=0.026)$ leg when donning and doffing their PPE. Table 2 provides relative normalized reach distance descriptive measures per assessment condition.

Table 2. Anterior Reach Normalized Results

\begin{tabular}{lccc}
\hline Condition & $\begin{array}{c}\text { Mean } \\
(\mathbf{c m})\end{array}$ & $\begin{array}{c}\text { Standard } \\
\text { Deviation } \\
(\mathbf{c m})\end{array}$ & $\begin{array}{c}\text { Standard } \\
\text { Error }(\mathbf{c m})\end{array}$ \\
\hline $\begin{array}{l}\text { Right Leg - } \\
\text { PPE }\end{array}$ & 69.23 & 21.26 & 2.72 \\
$\begin{array}{l}\text { Right Leg - } \\
\text { No PPE } \\
\text { Left Leg - }\end{array}$ & 72.72 & 22.19 & 2.84 \\
$\begin{array}{l}\text { PEE } \\
\text { Left Leg - } \\
\text { No PPE }\end{array}$ & 71.31 & 22.79 & 2.92 \\
\hline
\end{tabular}

PPE $=$ Personal Protective Equipment

\section{DISCUSSION}

In $2018,58,835$ firefighters were injured on the fireground. ${ }^{4}$ Strain or overexertion were the leading cause of fireground injuries. ${ }^{4}$ With the high rate and risk of injury during the job, firefighters are required to don PPE that limits smoke inhalation, chemical exposure, and fire contact resulting in burns. ${ }^{5}$ As a part of their PPE, 
firefighters must also wear a compressed air tank which was identified in previous literature to have a negative effect on postural control and functional balance. ${ }^{6}$ There are various PPE designs that are worn by firefighters, but regardless of the design, PPE significantly impairs functional balance. ${ }^{7}$ When donning PPE, firefighters had a decrease in movement speed by a $13 \%$ increase in performance time and made more errors on a balance exam. 7 By knowing that the PPE could impair functional balance, it is vital to understand how decreases functional balance may predispose a firefighter to a musculoskeletal injury on the fireground.

Results of this study found that there is a significant difference between the relative anterior reach distance for the right leg as compared to the left leg when patients are donning and doffing their PPE. Anterior reach decreased when donning PPE, due to the impairments of the functional balance. The anterior reach assessment was completed while donning and doffing firefighter PPE. Previous research has identified that the thermal layer (pants and jacket) alters a firefighter's gait speed during balance testing. PPE negatively effects gait by decreasing step length thus slowing one's speed. ${ }^{8}$

Although we were not assessing gait, we did identify that wearing the PPE significantly altered the firefighter's functional balance. Based on the literature, functional balance and gait are affected by donning PPE. This is of concern to the safety and wellness of the firefighters. The longer someone is in a live fire, the more functional balance is affected. If someone is moving slower and paired with balance decrements at the onset, there is a grave concern that exposure to heat while donning PPE may result in the trips and falls that contribute to the high statistics of sprains and strains in the United States fire service.

One mechanism that may improve functional balance while donning PPE is by increasing resistance and aerobic training, as the literature supports that a more physically active firefighter has less physical impairment. ${ }^{9}$ In regard to the limited anterior reach that was found in this study,

Copyright (C) by Indiana State University All rights reserved. ISSN Online 2577-8188 one proposed mechanism for the decrements is limited dorsiflexion at the ankle. Ankle dorsiflexion for firefighters is impacted by their boots. ${ }^{10-12}$ The literature supports that boot type (rubber versus leather) influences a firefighter's balance with rubber boots, increasing their risk for falls. ${ }^{10-12}$ Common tasks of firefighters include climbing ladders, emergency lifts to rescue victims in burning buildings, and assembling equipment to put out fires. As such, ankle dorsiflexion and functional balance are both required. Future research on PPE gear analysis would assist the industry in identifying how to create protective turnout gear that limits chemical exposure and exposure to fires that also allows for movement and range of motion.

\section{CLINICAL APPLICATION}

The data collected can assist in determining limitations that the patient's experiences with their PPE. This allows clinicians to be able to understand the potential causes of the mechanism of injury and design rehabilitation plans to prevent the injury from reoccurring. By determining the limitations during the mass screening, the clinician can work with the patient on goal setting and injury prevention. Due to the equipment having a negative effect on the patient's performance in the anterior reach, it may be beneficial to have the patient complete exercise, physical activity, and therapeutic rehabilitation with their PPE to train the body to replicate the conditions in which they are required to work. This change may result in more job-specific rehabilitation, with future investigations necessary to explore firefighters' ability to complete movements. Clinicians are also able to develop resistance and aerobic training exercise plans to increase the firefighter's overall physical fitness to reduce their physical impairments, which can result in improving their physical ability while donning PPE.

\section{REFERENCES}

1. Plisky PJ, Gorman PP, Butler RJ, Kiesel KB, Underwood FB, Elkins B. The reliability of an instrumented device for measuring 
components of the star excursion balance test. N Am J Sports Phys Ther. 2009;4(2):92.

2. haffer SW, Teyhen DS, Lorenson CL, et al. Ybalance test: a reliability study involving multiple raters. Mil Med.

2013;178(11):1264-1270.

https://doi.org/10.7205/milmed-d-1300222.

3. de la Motte SJ, Gribbin TC, Lisman P, Beutler $\mathrm{Al}$, Deuster P. The interrelationship of common clinical movement screens: establishing population-specific norms in a large cohort of military applicants. J Athl Train. 2016;51( 11 1):897-904. https://doi.org/10.4085/1062-605051.9.11.

4. Campbell R, Evarts B, Molis JL. United States Firefighter Injury Report 2018.National Fire Protection Association. 2019. Accessed at: https://www.nfpa.org/-/media/Files/Newsand-Research/Fire-statistics-andreports/Emergencyresponders/osffinjuries.pdf.

5. Guidotti TL, Clough VM. Occupational health concerns of firefighting. Annu Rev Public Health. 1992;13(1):151-171. https://doi.org/10.1146/annurev.pu.13.05 0192.001055.

6. Punakallio A, Lusa S, Luukkonen R. Protective equipment affects balance abilities differently in younger and older firefighters. Aviat Apace Environ Med. 2003;74(11):1151-1156.

7. Hur P, Hsiao-Wecksler E, Rosengren K, Horn G, Smith D. Effect of protective clothing and fatigue on functional balance of firefighters. J Ergonomics. 2013;2(004). https://doi.org/10.4172/2165-7556.S2$\underline{004}$.

8. Park K, Rosengren KS, Horn GP, Smith DL, Hsiao-Wecksler ET. Assessing gait changes in firefighters due to fatigue and protective clothing. Safety Science. 2011 ;49(5):719726. https://doi.org/10.1016/i.ssci.2011.01.012

Copyright $(9$ by Indiana State University 49 All rights reserved. ISSN Online 2577-8188
9. Kong PW, Suyama J, Cham R, Hostler D. The relationship between physical activity and thermal protective clothing on functional balance in firefighters. Res Q Exerc Sport. 2012 ;83(4):546-552. https://doi.org/10.1080/02701367.2012. 10599144.

10. Chiou SS, Turner N, Zwiener J, Weaver DL, Haskell WE. Effect of boot weight and sole flexibility on gait and physiological responses of firefighters in stepping over obstacles. Hum Factors. $2012 ; 54(3): 373$ 386.

https://doi.org/10.1177/0018720811433 464.

11. Garner JC, Wade C, Garten R, Chander H, Acevedo $\mathrm{E}$. The influence of firefighter boot type on balance. Int J Ind Ergon.

2013;43(1):77-81. http://dx.doi.org/10.1016\%2Fi.ergon.2012 .11 .002 .

12. Chander H, Garner JC, Wade C. Slip outcomes in firefighters: A comparison of rubber and leather boots. Occup Ergon. 2016;13(2):67-77. https://doi.org/10.3233/OER-160241. 